\title{
COMPARISON OF PROKINETIC ACTIVITY OF RANITIDINE AND NEOSTIGMINE ALONE AND IN COMBINATION- AN IN VITRO STUDY
}

\author{
Aroosa Ishtiaq Butt, Asma Khan, Wardha Mazhar*, Qamar Uz Zaman Khan**, Imrana Maqsood \\ Fazaia Medical College, Islamabad Pakistan, *Foundation University Medical College, Islamabad Pakistan, ${ }^{* *}$ Armed Forces Post Graduate \\ Medical Institute/National University of Medical Sciences (NUMS) Rawalpindi Pakistan
}

\begin{abstract}
Objective: To explore the prokinetic effect of Ranitidine, to compare it with the prokinetic effect of Neostigmine and to observe the potentiating prokinetic effect of Ranitidine and Neostigmine in combination.

Study Design: Randomised controlled trial (experimental study).

Place and Duration of Study: Multi disciplinary centre, Army Medical College, Rawalpindi, from Jan to Dec 2015. Methodology: Experiments were performed on three groups of rabbits $(n=6)$ and Cumulative dose response curves were plotted using isolated duodenal tissue on power lab (USA). In the first two groups of experiments, cumulative concentrations of Neostigmine and Ranitidine were studied separately with neostigmine acting as a control and in the third group the potentiating effect of a fixed dose of ranitidine on neostigmine was evaluated.

Results: Neostigmine's response was taken as 100 percent and Ranitidine's response when compared to it came out to be 197 percent. The dose response curve of Neostigmine was shifted to the left and upwards in the presence of Ranitidine. The percent response with Neostigmine alone was taken as 100 percent and increased to 212 percent when the tissue was pre-treated with Ranitidine.

Conclusion: Our study has indicated that Ranitidine has marked prokinetic effect which is found to be greater than Neostigmine. It is also inferred that Ranitidine can potentiate the prokinetic effect of Neostigmine.
\end{abstract}

Keywords: Neostigmine, Powerlab, Prokinetic, Ranitidine.

This is an Open Access article distributed under the terms of the Creative Commons Attribution License (http://creativecommons.org/licenses/by/4.0), which permits unrestricted use, distribution, and reproduction in any medium, provided the original work is properly cited.

\section{INTRODUCTION}

Gastroparesis is considered to be the main culprit of refractory/drug-resistant gastro-esophageal reflux disease (GERD). A probable 40 percent of these pharmacologically non-responders of GERD who in the end present to the surgical department for correcting the reflux are found to have causal gastroparesis. Anti-reflux surgery can cure GERD but not a chronic disorder like gastro-paresis. Gastroparesis, by itself can lead to GERD causing relaxation of the lower oesophageal sphincter by distending the stomach which causes symptoms of reflux, by causing food to accumulate in the stomach which stimulates the production of gastric acid and by retrograde increase in the volume and pressure in the stomach which ultimately leads to an appreciable increase in the volume of reflux. The symptomatic overlap

Correspondence: Dr Aroosa Ishtiaq Butt, Pharmacology Dept, Fazaia Medical College, Islamabad Pakistan

Received: 26 Mar 2019; revised received: 12 Dec 2019; accepted: 20 Dec 2019 between gastroparesis and GERD makes it difficult to differentiate them clinically ${ }^{1}$.

Prokinetic drugs are fore front of pharmacological therapy for gastroparesis patients. These drugs expedite the propulsive passage of food via the gut by increasing the motor activity ${ }^{2}$. Conventionally, the drugs which augment the cholinergic stimulation, be it by direct or indirect measures are the mainstay of the remedial treatment. Blockers at the dopamine receptor type-2 (D2) inhibits the negative impact of dopamine on cholinergic nerve endings in the gut and thus, increases the motility of the gut. Ranitidine and similar drugs retarding acid secretion are employedin conjunction with pro-kinetic drugs for treating gastro paresis. GERD which occurs in recumbent position entails suppression of acid secretion with ranitidine as it is proven to be better than the proton pump inhibitors ${ }^{3}$.

Ranitidine has long known to be a blocker at the histamine type-2 receptors (H2) present at the parietal cell of the lining of the stomach. Hista- 
mine antagonism inhibits acid release from the stomach, prompting its use as an anti-ulcer drug. Elegant studies have revealed definite Gastrointestinal (GI) motility enhancing activity of Ranitidine which is better than cimetidine and some known prokinetic agents ${ }^{4}$. Some studies do indicate that Ranitidine also has a pro-kinetic activity possibly by virtue of its ability to block Acetyl cholinesterase enzyme leading to decreased metabolism of acetylcholine which leads to an increase in GI motility 5 .

The ease of dosing, superior safety profile and less probability for drug-drug interaction has provided ranitidine an edge over its counterpart cimetidine $^{6}$. Ranitidine is indicatedin GERD, gastric ulcers, Zollinger-Ellison syndrome and hyper-secretory states 7 . Ranitidine fortunately is a relatively well tolerated drug with very few side effects which include diarrhoea and headache?.

Neostigmine is a known inhibitor of the enzyme that degrades Ach which is called as acetyl cholinesterase (AchE), and thus increases levels of this neurotransmitter in the synaptic gap. The increased levels of Ach thus bind to the post synaptic acetylcholine receptors leading to increased parasympathetic stimulation ${ }^{8}$. Neostigmine promotes the motor activity of the gut by increasing the parasympathetic activity by reversibly inhibiting Ach E. Therefore it works only if the release of Ach and the function of smooth muscle are intact ${ }^{9}$.

Neostigmine is clinically used in Ogilvie's syndrome (acute colonic pseudo-obstruction) and to treat postoperative ileus 10,11 . The most common adverse effects of neostigmine include cramps in the abdomen, vomiting, hypersalivation and bradycardia ${ }^{12}$.

The rationale of this study was to explore the intestinal stimulatory activity of ranitidine and to compare it with neostigmine both alone and in combination on isolated duodenal tissue of rabbits. This study will determine if the combined effect of the prokinetic neostigmine is greater when given in combination with ranitidine.

\section{METHODOLOGY}

This was a randomised controlled trial (experimental study) which was conducted at the multi disciplinary centre, Army Medical College, Rawalpindi and duration of the study was 01 year. Locally purchased, healthy looking rabbit's (Oryctalagus cuniculus) of either sex, male/ female, weighing around $2 \mathrm{~kg}$ were included for this project using the consecutive sampling technique. They were made to adapt to the new atmosphere for around 8 days at animal keeping facility of Army Medical College. The conditions were standard that is, a light/dark cycle of 12 hours, temperature of $24^{\circ} \mathrm{C}$ and humidity level of around 60 percent. Standard food comprising carrots, choker and grain along with tap water was provided to the animals ad libitum. Ranitidine and Neostigmine (Sigma Chemical Co. USA) were purchased. All the dilutions were freshly prepared at the time of the experiments ${ }^{13}$. Ranitidine in a dose of $(1.4-70 \mu \mathrm{g})^{14}$ and Neostigmine in doses of $(0.08 \mu \mathrm{g}-0.64 \mu \mathrm{g})$ were employed for the study ${ }^{15}$. Rabbits underwent fasting overnight to empty the bowels following which they were sacrificed in the morning. The small intestine was isolated by spotting the caecum ${ }^{16}$. Normal saline was poured over the intestine carefully with removal of any residual fecolith. Whole of the small intestine (duodenum, jejunum and terminal ileum) was cut out and then carefully placed in Tyrode's solution. The duodenum was identified by tracing back the small intestine after recognition of the caecum. Duodenum was cut into pieces. The duodenum was put insidethe organ bath $(50 \mathrm{ml})$ containing Tyrode's solution and bubbled with 100 percent $\mathrm{O} 2^{17}$ and maintained at a temperature of $37 \pm 2^{\circ} \mathrm{C}^{15}$. One end of the duodenum was tied to the bottom of the oxygen tube bath and the other was attached to a Research Grade Isometric Force Transducer DT-475-USA by the help of a silk thread. The isotonic duodenal muscle movements was measured by this Displacement Transducer ${ }^{18}$. Cumulative dose-response curves were constructed using enhancing concentrations of Neostigmine and Ranitidine. The third set of experiments was performed by taking a 
sub-maximal dose ofranitidine for exploring the combined effects of the two. The selected fixed dose of ranitidine was allowed to react with the duodenal tissues in the organ bath and then cumulatively increasing concentrations of Neostigmine were employed to see the potential synergism between the two drugs. Each tissue was used for one particular concentration response curve to prevent desensitization. Response of neostigmine was supposed as 100 percent and response of Ranitidine was compared with it.

Results are expressed as Means \pm Standard Deviation. The arithmetic means of responses of contractile activity of isolated duodenum were calculated. The percent responses and percentage enhancement were derived using the Microsoft Office Excel 2013. Independent Sample t-test was applied for comparing two groups and a value of $p<0.05$ was considered as statistically significant.

\section{RESULTS}

Neostigmine's response was taken as 100 percent and the response of Ranitidine compared to it was 197 percent. The dose response curve of calculated and the response of $0.32 \mu \mathrm{g}$ was taken as 100 percent. The percent responses to other concentrations were 75, 80, 97 and 94 percent respectively.

Results group-2: Ranitidine $(1.4 \mu \mathrm{g}, 2.1 \mu \mathrm{g}$, $2.8 \mu \mathrm{g}, 7.0 \mu \mathrm{g}, 14.0 \mu \mathrm{g}, 28.0 \mu \mathrm{g}, 35.0 \mu \mathrm{g}$, and 70.0 $\mu \mathrm{g})$ produced a mean \pm SD of response of $0.080 \pm$ $0.009 \mathrm{mV}, 0.086 \pm 0.009 \mathrm{mV}, 0.092 \pm 0.010 \mathrm{mV}$, $0.100 \pm 0.024 \mathrm{mV}, 0.111 \pm 0.022 \mathrm{mV}, 0.124 \pm 0.034$ $\mathrm{mV}, 0.136 \pm 0.026$ and $0.123 \pm 0.019 \mathrm{mV}$ respectively. The percent responses to $35 \mu \mathrm{g}$ was determined as 100 percent and the responses to other mentioned concentrations were calculated as 59, $63,68,73,82,91$, and 90 percent respectively.

Results group-3: The mean \pm SD responses to cumulatively increasing concentrations of neostigmine $(0.08 \mu \mathrm{g}, 0.16 \mu \mathrm{g}, 0.24 \mu \mathrm{g}, 0.32 \mu \mathrm{g}$ and $0.40 \mu \mathrm{g})$ in the presence of fixed dose $(28 \mu \mathrm{g})$ of Ranitidine are $0.118 \pm 0.022 \mathrm{mV}, 0.121 \pm 0.042 \mathrm{mV}$, $0.135 \pm 0.021 \mathrm{mV}, 0.146 \pm 0.035 \mathrm{mV}$ and $0.133 \pm$ $0.024 \mathrm{mV}$ respectively. The percent response for eachsequential dose of neostigmine was calculated by taking the maximum response of neostigmine alone as maximum $(0.069 \mathrm{mV})$ and then all

Table: Response of isolated duodenum of rabbits in the presence of cumulatively increasing concentrations of neostigmine.

\begin{tabular}{|c|c|c|c|c|c|c|}
\hline $\begin{array}{l}\text { Dose of } \\
\text { neostigmine } \\
(\mu \mathrm{g})\end{array}$ & $\begin{array}{c}\text { Log } \\
\text { Dose }\end{array}$ & $\begin{array}{c}\text { Response on } \\
\text { isolated duodenum } \\
(\text { mean } \pm S D)(\mathrm{mV}) \\
\mathrm{n}=6\end{array}$ & $\begin{array}{c}\text { Mean response of } \\
\text { ranitidine and } \\
\text { neostigmine (mean } \pm \\
\text { SD) }(\mathrm{mV}) \mathrm{n}=6\end{array}$ & $\begin{array}{c}\text { Percent } \\
\text { Response of } \\
\text { neostigmine } \\
\text { alone }(\%)\end{array}$ & $\begin{array}{c}\text { Percent } \\
\text { Response of } \\
\text { ranitidine and } \\
\text { neostigmine }(\%)\end{array}$ & $\begin{array}{c}p- \\
\text { value }\end{array}$ \\
\hline 0.08 & 1.9 & $0.052 \pm 0.029$ & $0.118 \pm 0.022$ & 75 & 171 & 0.0047 \\
\hline 0.16 & 2.2 & $0.055 \pm 0.029$ & $0.121 \pm 0.042$ & 80 & 175 & 0.0120 \\
\hline 0.24 & 2.4 & $0.067 \pm 0.029$ & $0.135 \pm 0.021$ & 97 & 196 & 0.0066 \\
\hline 0.32 & 2.5 & $0.069 \pm 0.034$ & $0.146 \pm 0.035$ & 100 & 212 & 0.0122 \\
\hline 0.40 & 2.6 & $0.065 \pm 0.030$ & $0.133 \pm 0.024$ & 94 & 192 & 0.0027 \\
\hline
\end{tabular}

Neostigmine was shifted to the left and upwards in the presence of Ranitidine. The percent response with Neostigmine alone was taken as 100 percent and increased to 212 percent when the tissue was pre-treated with Ranitidine.

Results group- 1 : Neostigmine $(0.08 \mu \mathrm{g}, 0.16$ $\mu \mathrm{g}, 0.24 \mu \mathrm{g}, 0.32 \mu \mathrm{g}$ and $0.40 \mu \mathrm{g})$ produced a mean \pm SD response of $0.052 \pm 0.029 \mathrm{mV}, 0.055 \pm 0.029$ $\mathrm{mV}, 0.067 \pm 0.029 \mathrm{mV}, 0.069 \pm 0.034 \mathrm{mV}$ and 0.065 $\pm 0.030 \mathrm{mV}$ respectively. For all the above stated doses of the drug, the percent responses were the responses of ranitidine and neostigmine were compared with it and came out to be 171, 175, 196, 212 and 192 percent respectively.

Comparison of groups 1, 2 and 3

Response of neostigminealone was taken as 100 percent and response of Ranitidine alone when compared with it came out to be 197 percent. The response increases to 212 percent when the two are used in combination. The mean \pm SD values of groups 2 and 3 were found to be highly statistically significant $(p=0.007)$. The per- 
cent responses of group 2 when compared with group 3 were found to be significant statistically $(p<0.05)$. The log dose response curve of ranitidine and neostigmine when plotted with neostigmine alone was shifted to the left and upwards as shown in fig- 2 .

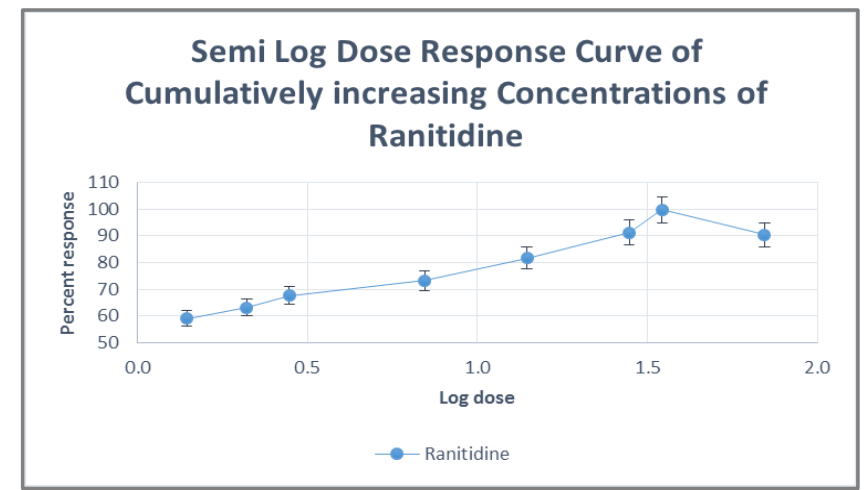

Figure-1: Semi log dose response curve of ranitidine.

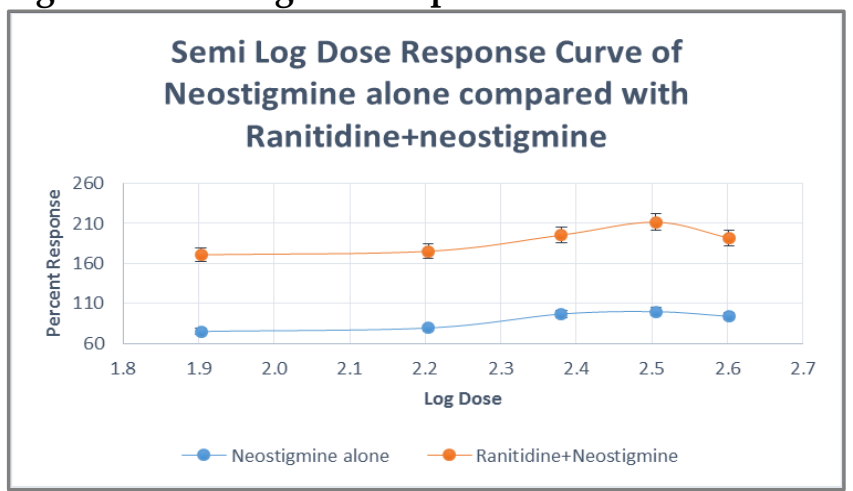

Figure-2: Semi Log dose response curve of neostigmine alone (blue) compared with Log dose response curve of neostigmine when pretreated with a fixed dose of ranitidine (orange).

\section{DISCUSSION}

The first group of experiment was carried out to observe the prokinetic activity of neostigmine which is an anti-acetylcholinesterase. Neostigmine produced a reversible dose dependent prokinetic response when added at cumulatively increasing concentrations of $0.08-0.40 \mu \mathrm{g}$. The maximum response as recorded by Power-Lab was $0.069 \mathrm{mV}$. This group served as a control for our study.

In the second group of experiments, the prokinetic activity of ranitidine was recorded by adding cumulatively increasing concentrations of the drug on isolated duodenum of rabbits. Rani- tidine produced a marked increase in the amplitude of contractions of isolated duodenum at cumulatively enhancing concentrations of 10-510-3 M. The dose range established for these concentrations were 1.4-70 $\mu \mathrm{g}$. Ranitidine produced a maximum response of $0.136 \mathrm{mV}$ at $35 \mu \mathrm{g}$ as recorded by a Displacement Transducer on iWorx/ 214. Kusano with his co-researchers anticipated ranitidine's role in causing enhanced transmission of cholinergic activity ${ }^{19}$. Zaidescribed the process by which ranitidine increases the motility of the gastrointestinal tract. According to him ranitidine increases the levels of acetylcholine by directly acting as agonists at the cholinergic receptors. It may also be by an indirect role that is by augmenting the release of acetylcholine from cholinergic nerve endings or by inhibiting the enzyme acetylcholinesterase ${ }^{20}$. It was observed by Kounenis et al that ranitidine dose dependently enhanced the acetylcholine sensitive contractile activity of the gastrointestinal tract and the effect was more pronounced on the duodenum as compared to ileum, hence the selection of duodenum for this research project ${ }^{14}$.

The efficacy of ranitidine as a prokinetic agent was compared with neostigmine. The mean response of ranitidine of all six experiments was $0.136 \mathrm{mV}$ and was greater than the mean responses of neostigmine $0.069 \mathrm{mV}$. The response of neostigmine was taken as 100 percent and the response of Ranitidine when compared with it came out to be 197 percent. The prokinetic potential of ranitidine was found to be greater than neostigmine and our result is in accordance with a study carried out by Bortolottis. In 1995 Bortolotti and his co-workers compared the prokinetic activity of ranitidine and neostigmine in patients of idiopathic gastroparesis and concluded that ranitidine enhanced the phase 3 motor activity of the gut independent of its cholinergic action and is thus a stronger prokinetic compared to neostigmine ${ }^{21}$.

The potential ability of ranitidine to increase the contractile effect of neostigmine was studied in the third set of experiments where a fixed dose of ranitidine enhanced the contractile effect of 
neostigmine in vitro. The fixed dose of ranitidine selected was $0.8 \mathrm{ml}$ of $10-4 \mathrm{M}$ i.e. $28 \mu \mathrm{g}$. The maximum response of $0.32 \mu \mathrm{g}$ of neostigmine when pre-treated with a fixed dose of ranitidine was increased to $0.146 \mathrm{mV}$ as opposed to $0.069 \mathrm{mV}$ when neostigmine was used alone. When neostigmine was added with ranitidine, the dose response curve was shifted to the left and upwards compared to the dose response curve of neostigmine alone. The percent response when neostigmine was given alone was 89 percent and was increased to 189 percent when pre-treated with ranitidine. The percentage enhancement of the contractile effect of neostigmine and ranitidine was 113 percent. Our findings revealed that the combination of neostigmine and ranitidine enhanced the gut contractility as compared to when neostigmine was used alone. According to a study conducted by Bortolotti et al, neostigmine was not found to be superior to ranitidine for the symptomatic relief of gastroparesis ${ }^{21}$.

\section{CONCLUSION}

Our study concludes with the finding that Ranitidine apart from being a well-known $\mathrm{H} 2$ blocker also has a marked prokinetic effect. Its prokinetic efficacy is better than the signature prokinetic drug neostigmine. We also recommend that ranitidine can be more effective in gastric paretic conditions either alone or in combination with other prokinetic agents.

\section{CONFLICT OF INTEREST}

There is no conflict of interest to be declare by any author.

\section{REFERENCES}

1. Leeds SG, Pescarus R, Dunst CM. Delayed gastric emptying and reflux disease. Antireflux Surgery: Springer 2015; 1(1): 197203.

2. Hejazi RA, McCallum RW, Sarosiek I. Prokinetics in diabetic gastroparesis. Curr Gastroenterol Rep 2012; 14(4): 297-305.

3. Xue S, Katz P, Banerjee P, Tutuian R, Castell D. Bedtime H2 blockers improve nocturnal gastric acid control in GERD patients on proton pump inhibitors. Aliment Pharmacol Ther 2001; 15(9): 1351-56.

4. Sakakibara R, Sato M, Hirai S, Masaka T, Kishi M, Tsuyusaki $\mathrm{Y}$, et al. Nizatidine ameliorates gastroparesis in Parkinson's disease: A pilot study. Mov Disord 2014; 29(4): 562-66.
5. Parkman HP, Pagano AP, Ryan JP. Ranitidine and nizatidine stimulate antral smooth muscle contractility via excitatory cholinergic mechanisms. Dig Dis Sci 1998; 43(3): 497-505.

6. Madani S, Kauffman R, Simpson P, Lehr VT, Lai ML, Sarniak A, et al. Pharmacokinetics and pharmacodynamics of famotidine and ranitidine in critically ill children. J Clin Pharmacol 2014; 54(2): 201-05.

7. Aouam K, Bouida W, Ben Fredj N, Chaabane A, Boubaker H, Boukef $\mathrm{R}$, et al. Severe ranitidine-induced anaphylaxis: A case report and literature review. J Clin Pharm Ther 2012; 37(4): 494-96.

8. Gebre-Giorgis AA, Roderique EJD, Stewart D, Feldman MJ, Pozez AL. Neostigmine to relieve a suspected colonic pseudoobstruction in a burn patient: a case-based review of the literature. Eplasty 2013; 13: e1-9.

9. Parthasarathy G, Ravi K, Camilleri M, Andrews C, Szarka L, Low $\mathrm{P}$, et al. Effect of neostigmine on gastroduodenal motility in patients with suspected gastrointestinal motility disorders. J Neurogastroenterol Motil 2015; 27(12): 1736-46.

10. Cellini J, DiNovo K, Harlow J, LePard KJ. Regional differences in neostigmine-induced contraction and relaxation of stomach from diabetic guinea pig. Auto Neurosci 2011; 160(1): 69-81.

11. Aghadavoudi $\mathrm{O}$, Abbasi S, Kashefi P, Golparvar M, Habibzade M, Kazemi S. Evaluation of intravenous neostigmine infusion on tolerance of enteral nutrition in Intensive Care Unit patients. J Res Med Sci; J Isfahan Uni Med Sci 2013; 18(9): 750.

12. Ponec RJ, Saunders MD, Kimmey MB. Neostigmine for the treatment of acute colonic pseudo-obstruction. New England J Med 1999; 341(3): 137-41.

13. Noor A, Najmi M, Bukhtiar S. Effect of Montelukast on bradykinin-induced contraction of isolated tracheal smooth muscle of guinea pig. Ind J Pharmacol 2011; 43(4): 445-49.

14. Koutsoviti-Papadopoulou M, Nikolaidis E, Batzias G, Kounenis G. Synergistic and antagonistic pharmacodynamic interaction between ranitidine and cisapride: a study on the isolated rabbit intestine. Pharmacological Res 2001; 43(4): 329-34.

15. Chiragh S, Begum A, Karim S. Prokinetic effect of clarithromycin and azithromycin-in vitro study on rabbit duodenum. Biomedica 2006; 22(1): 130-34.

16. Jabeen $\mathrm{Q}$, Aziz N, Gilani A. The spasmogenic and spasmolytic activities of Lavandula stoechas are mediated through muscarinic receptor stimulation and calcium channel blockade. Int J Pharmacol 2007; 3(1): 61-67.

17. Tanko Y, Alladey O, Ahmed M, Mohammed A, Musa K. The effect of methanol leaves extract of Ficus glumosa on gastrointestinal motility and on castor oil induced diarrhea in laboratory animals. J Natural Prod Plant Res 2012; 2(3): 360-67.

18. Chetty N, Irving HR, Coupar IM. Activation of 5-HT3 receptors in the rat and mouse intestinal tract: a comparative study. Br J Pharmacol 2006; 148(7): 1012-21.

19. Kusano M, Hosaka H, Kawada A, Kuribayashi S, Shimoyama Y, Zai H, et al. Gastrointestinal motility and functional gastrointestinal diseases. Curr Pharmaceutical Des 2014; 20(16): 2775-82.

20. Zai H, Matsueda K, Kusano M, Urita Y, Saito Y, Kato H. Effect of acotiamide on gastric emptying in healthy adult humans. Eur J Clini Invest 2014; 44(12): 1215-21.

21. Bortolotti M, Cucchiara S, Sarti P, Brunelli F, Mazza M, Bagnato $F$, et al. Comparison between the effects of neostigmine and ranitidine on interdigestive gastroduodenal motility of patients with gastroparesis. Digestion 1995; 56(2): 96-99. 